\title{
Plâncton e produçào primária em sistemas aquáticos da bacia da Amazônia Central (*)
}

\author{
Thomas R. Fisiner (')
}

\begin{abstract}
Resumo
Três ambientes aquáticos da bacia da Amazônia Central foram amostrados durante a fase de águas baixas: rio Solimões (Amazonas), rio Negro e lago Janauacá. No rio Solimões, rico em nutrientes, a produtividade primária foi em média $0,063 \mathrm{~g} \mathrm{C} / \mathrm{m}^{2} . \mathrm{d}$, porém o crescimento líquido de fitoplâncton é impossível devido à profundidade, pouca penetração de luz e turbulência causada pela correnteza. No rio Negro, quimicamente pobre, um ciclo diário de $\Sigma \mathrm{CO}_{2}$ foi causado pela demanda fotossintética nas águas superficiais, $\theta$ a produtividade primária foi em média $0,19 \mathrm{~g} \mathrm{C} / \mathrm{m}^{2}$.d. No lago Janauacá, um lago marginal do Solimōes, os nutrientes apresentavam baixa concentração eram intensamente reciclados; grandes populações de fitoplâncton produziram até $3,5 \mathrm{~g} \mathrm{C} / \mathrm{m}^{2}$.d (média $=2,2$ ). A mudança anual de dez metros no nível da água do Amazonas fornece e drena a maior parte da água nos lagos marginais. Durante a estocagem da água do rio nos lagos a matéria particulada sedimenta-se e os nutrientes inorgânicos dissolvidos são convertidos para formas inorgânicas pelo intenso crescimento do fitoplancton. Estes lagos podem ser uma importante fonte de matéria orgânica para o ecossistema fluvial.
\end{abstract}

\section{INTRODUÇÃO}

O rio Amazonas, seus lagos e tributários constituem o maior sistema fluvial do mundo, drenando aproximadamente $37 \%$ da América do Sul Continental (Gresswell \& Huxley, 1964). Como resultado da grande bacia de drenagem e da elevada precipitação anual (aproximadamente $2 \mathrm{~m} / \mathrm{ano}$ ) (Sioli, 1964), a descarga do rio Amazonas constitui $18 \%$ do total de água doce da drenagem terrestre que chega aos oceanos do mundo (Davis, 1964; Gibbs, 1967).

O padrão sazonal dominante na bacia em grande parte tropical do rio Amazonas é a subida e descida de dez metros do sistema fluvial que anualmente inunda e drena grandes áreas adjacentes aos rios, inclusive muitos lagos marginais. Este padrão é acionado pela distribuição anual da precipitação. Nível baixo ocorre tipicamente em novembro, e nível alto em junho (Oltman et al., .964).

Sioli (1964) descreveu três tipos gerais de águas encontrados dentro da bacia Amazônica: água branca, preta e clara. Agua branca é a água turva, de coloração "café com leite", do curso principal do Amazonas; ela deriva $85 \%$ de sua carga em suspensão e dissolvida das bordas montanhosas da área de drenagem (Gibbs, 1967). Água preta é transparente, altamente tingida, e drena podzóis das áreas baixas (Klinge, 1967). Agua clara drena sedimentos terciários dos planos na parte sudeste da bacia (Sioli, 1964). Uma quarta categoria geral pode ser encontrada nos lagos da bacia Amazônica: água branca decantada (Schmidt, 1973a), que é a água remanescente nos lagos da invasão da estação úmida anterior pelas águas brancas dos rios, e da qual a maior parte das partículas se depositou.

Várias investigações gerais dos padrōes anuais da biomassa do fitoplâncton e da produtividade primária foram feitas para alguns destes tipos de águas (Schmidt, 1970, 1973b, 1976), especialmente com relação às flutuações sazonais do nível de água. Entretanto, pouca informação encontra-se disponivel sobre os constituintes minerais mais importantes necessários para o crescimento do fitoplâncton (e, portanto, para a produção primária): amônia, nitrato e fosfato. Com o intuito de obter-se alguns destes dados sobre os diferentes tipos de água da bacia da Amazônia Central, a pesquisa aqui relatada foi conduzida durante a IV Expedição Amazônica do "Alpha Helix" em novembro e dezembro de 1976.

(•) - Versão original inglesa publicada em Comp. Biochem. Physiol. vol. 62A (1). 1979

(1) - Duke University Marine Laboratory, Beaufort, N.N. 28516. 
MÉTodos

Amostras da água superficial foram coletadas em 13 estaçōes representando três ambientes aquáticos da região da Amazônia Central próxima a Manaus, Brasil: (1) água preta - rio Negro; (2) água branca - rio Solimões (Amazonas); e (3) água branca decantada lago de Janauacá. No espaço de tempo de uma hora, após a coleta, foram feitas análises em duplicata da concentração de amônia, nitrato + nitrito, e fosfato reativo, usando-se técnicas miniaturizadas em subamostras filtradas. Amônia foi determinada pelo método de Koroleff (1969); 200 ul de reagente A e B foram adicionados a $7,00 \mathrm{ml}$ das amostras; uma amostra ao acaso de dez pares em duplicata forneceu um coeficiente de variação médio ( $100 \%$ X desvio padrão/média) de $16 \%$ ao nível de 4 ug-at N/1. Fosfato reativo foi determinado pelo método de Strickland \& Parsons (1972); $1000 \mathrm{ul}$ de reagentes misturados foram adicionados a $10,0 \mathrm{ml}$ das amostras; o coeficiente de variação como descrito acima foi de $13 \%$ ao nível de 0,4 ug-at $P / 1$. Nitrato e nitrito foi medido pelo método de Strickland \& Parsons (1972) modificado por E.B. Haines (com. press.). Colunas de redução de $\mathrm{Cd}-\mathrm{Cu}$ foram feitas de pipetas de Pasteur e funis de plástico; 100 ul do reagente $A$ e $B$ foram adicionados a $5,00 \mathrm{ml}$ do efluente da coluna; uma eficiência da redução do nitrato maior do que $95 \%$ foi obtida, e nenhuma correção foi feita para a redução do nitrito; o coeficiente de variação como descrito acima foi $8,3 \%$ ao nível de 7 ug-at $\mathrm{N} / 1$.

Seston (material particulado total) foi determinado gravimetricamente usando filtros de fibra de vidro pré-pesados; o coeficiente de variação foi $10 \%$ ao nível de $60 \mathrm{mg} / 1$. Nitrogênio particulado (NP) foi medido por combustão dos filtros de seston num analisador de nitrogênio Coleman modelo 29; o coeficiente de variação foi $9,9 \%$ ao nível de 140 ug N/1. Carbono orgânico particulado (COP) foi medido sobre filtros de prata de $0,8 \mu$ (Selas-Flotronics), que foram queimados num analisador de $\mathrm{C}$ - $\mathrm{H}$ Coleman modificado segundo Menzel e Vacarro (1964); o coeficiente de variação foi $12 \%$ ao nível de $20 \mathrm{ug} / 1$. $\mathrm{O} \mathrm{pH}$ das amostras de água foi medido com um peagâmetro Beck- man e respectivo eletrodo de vidro calibrado com solução tampão de $\mathrm{pH}=7,0$ antes de cada uso. COP e NP foram medidos sobre filtros enviados aos EE.UU; todas as outras análises foram realizadas a bordo.

Amostras totais de água foram preservadas com solução de Lugol para determinação da abundância de fitoplâncton. As amostras foram examinadas posteriormente nos EE.UU. usando uma técnica de sedimentação (Vollenweider, 1974). Algas foram identificadas a partir dos tratamentos taxonômicos da flora amazônica (Forster, 1969; Scott et al. 1965; Thomasson, 1971) suplementados com trabalhos de referência sobre a flora algológica norteamericana (Whitford e Schumacher, 1973; Prescott, 1962; Smith, 1933) .

Medidas similares in situ da produção primária foram feitas três horas após a coleção. As amostras foram mantidas sob luz reduzida durante este intervalo. As amostras de água foram colocadas em garrafas de $125 \mathrm{ml}$ com tampa de vidro e injetadas com 5 uCi de ${ }^{14} \mathrm{CO}_{2}$ livre. As garrafas foram encerradas dentro de telas calibradas simulando os regimes da luz in situ (Kiefer \& Strickland, 1970) e colocadas numa incubadora refrigerada a água durante 1-4 horas. A absorção de ${ }^{14} \mathrm{C}$ foi medida por contagem de cintilação líquida (PCS) de uma amostra particulada (millipone $0,8 \mathrm{u}$ ) de cada garrafa; numa correção para o tempo zero foi usado (Huntsman, 1974). A calibração do contador de cintilação líquida Beckman feita pelo método da razão dos canais usando um padrão de ${ }^{14} \mathrm{C}$ preparado. Análises duplicadas do dióxido de carbono dissolvido total $\left(\mathrm{CO}_{2}+\right.$ $\mathrm{H}_{2} \mathrm{CO}_{3}+\mathrm{HCO}_{3}^{-}+\mathrm{CO}_{3}==\sum \mathrm{CO}_{2}$ ) foram efetuadas pela remoção total dos gases da amostra de água, seguida por medidas da concentração de $\mathrm{CO}_{2}$ num analisador infravermeIho de gases Beckman 215 B; curvas padrão foram preparadas usando injeçōes de $\mathrm{CO}_{2}$ seco; o coeficiente de variação foi $5,7 \%$ ao nível de 300 ug-at $C / 1$. A produtividade horária foi calculada integrando a produção ao longo da profundidade; a produtividade diária foi calculada usando dados obtidos em diversos dias quando a produtividade horária foi somada para todas as horas de luz do dia (exemplo na fig. 1). 


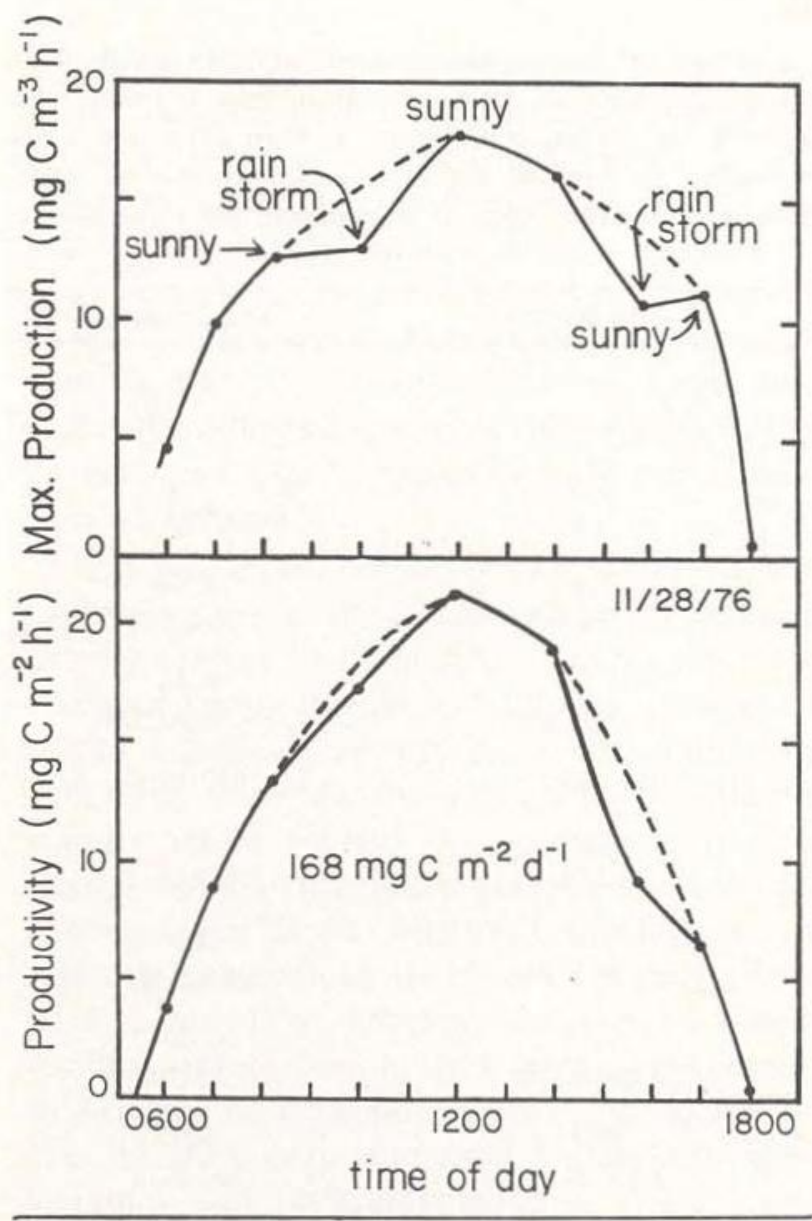

Fig. 1 - Produtividade primária de carbono pelo fitoplancton no baixo rio Negro, Brasil. O gráfico superior é a produção máxima observada na coluna d'água durante o período de tempo; o gráfico inferior é a produtividade integrada em toda a profundidade. Condiçōes de baixa luminosidade associadas com tempestades de chuva diminuem a taxa de fixação de carbono.

A perda de carbono orgânico marcado pelo fitoplâncton ("excreção"; Sharp, 1977) foi medida contando-se amostras filtradas e purgadas das garrafas. Alíquotas filtradas foram acidificadas até $\mathrm{pH} 3$, borbulhadas rapidamente com ar durante dez minutos, e então contadas no PCS. Um estudo inicial mostrou que sob as condições usadas, as contagens obtidas eram constantes após cinco minutos de remoção de dióxido de carbono. Dez minutos de aeração foi usado como uma margem de segurança para evitar altas contagens devidas erroneamente a ${ }^{14} \mathrm{CO}_{2}$. Uma amostra no tempo zero", livre de $\mathrm{CO}_{2}$, foi usada para corrigir qualquer contaminação por carbono orgânico marcado.
Dragagens de zooplâncton foram feitas com uma rede $n^{\circ} 10$ de um barco remado lentamente durante 2-5 minutos. O volume de filtraçăo foi calculado a partir do tempo registrado, velocidade estimada do barco, e área da seção transversal de rede, assumindo uma eficiência de filtração de $50 \%$, visto que as redes ficavam extremamente entupidas com o material mesmo dentro de dois minutos. O material filtrado foi gelado para matar os organismos, deixado decantar durante 3-6 horas em tubos graduados e o volume registrado. A separação qualitativa deu como estimativa que $95 \%$ do material filtrado do lago era zooplâncton. Face às densas populações no lago Janauacá, amostras totais de água foram também examinadas para a abundância do zooplâncton. Amostras de $10-20 \mathrm{ml}$ de água foram colocados numa placa de Petri rasa, algumas gotas de formol ${ }^{10}$ eram adicionadas para matar o zooplâncton. Após sedimentação, os animais eram contados sob uma lupa de dissecção de baixo aumento. A densidade foi calculada como número/volume.

\section{Resultados}

Os três ambientes aquáticos da bacia da Amazônia Central que foram amostrados durante a fase de águas baixas (nov.-dez.) de 1976 eram distintamente diferentes com respeito à biomassa de plâncton, nutrientes minerais dissolvidos e produtividade primária, Os resultados estão sumarizados nas tabelas I e II.

No rio Solimões, rico em nutrientes, a produtividade primária foi muito baixa face à deficiente penetração de luz causada pela turbidez. A zona eufótica (maior do que $1 \%$ da luz incidente) era sempre menos do que um metro em profundidade, enquanto a profundidade de mistura era provavelmente sempre até o fundo (20-40 m de profundidade) dada a turbulência associada com a forte correnteza $(1-2 \mathrm{~m} / \mathrm{seg}$.) . Portanto, as células de algas no rio Solimões estão expostas a níveis significativos de luz durante apenas pequenas frações do tempo, o crescimento líquido parece ser impossivel porque a respiração irá exceder a fotossíntese sob estas condições 
TABELA I. Média (e amplitude de variação) das concentrações de nutrientes inorgânicos, matéria particulada e produtividade primária do fitoplâncton em três ambientes aquáticos da bacia da Amazônia Central. Rio Solimões (= Amazonas) é um rio de água branca; rio Negro é um rio de água preta; e, lago Janauacá é um lago marginal do rio Solimões e contém água branca decantada. As médias do lago refletem valores anteriores à invasão. A profundidade de Sechi é inversamente relacionada com o coeficiente de extinção da luz da coluna d’água.

\begin{tabular}{|c|c|c|c|}
\hline & Rio Amazonas & Rio Negro & Lago Janauacá \\
\hline $\begin{array}{l}\text { Dióxido de carbono } \\
\text { total }\left(\sum \mathrm{CO}_{2}, \mu \mathrm{m}\right)\end{array}$ & $\begin{array}{c}420 \\
(130-670)\end{array}$ & $\begin{array}{l}38 . \\
(13 .-100)\end{array}$ & $\begin{array}{c}150 \\
(91 .-240)\end{array}$ \\
\hline $\begin{array}{l}\text { Amônia } \\
\left(\mathrm{NH}_{3} \mu \mathrm{m}\right)\end{array}$ & $\begin{array}{c}3.5 \\
(0.12-8.4)\end{array}$ & $\begin{array}{l}3.9 \\
(1.7-9.1)\end{array}$ & $\begin{array}{c}1.5 \\
(0.73-3.0)\end{array}$ \\
\hline $\begin{array}{l}\text { Nitrato }+ \text { Nitrito } \\
\left(\mathrm{NO}_{3}+\mathrm{NO}_{2}, \mu \mathrm{m}\right)\end{array}$ & $\begin{array}{l}12 . \\
(6.6-16.0)\end{array}$ & $\begin{array}{c}2.9 \\
(1.6-5.4)\end{array}$ & $\begin{array}{c}0.10 \\
(0-0.20)\end{array}$ \\
\hline $\begin{array}{l}\text { Fosfato } \\
\left(\mathrm{PO}_{4}, \mu \mathrm{m}\right)\end{array}$ & $\begin{array}{c}0.90 \\
(0.65-1.3)\end{array}$ & $\begin{array}{l}0.20 \\
(0.06-0.47)\end{array}$ & $\begin{array}{c}0.14 \\
(0.083-0.27)\end{array}$ \\
\hline $\mathrm{C}: \mathrm{N}: \mathrm{P}$ atômicos & $460: 17: 1$ & $240: 45: 1$ & $850: 12: 1$ \\
\hline $\begin{array}{l}\text { Matéria particulada } \\
\text { total }(\mathrm{mg} / 1)\end{array}$ & $\begin{array}{c}89 . \\
(46,-220)\end{array}$ & $\begin{array}{l}23 . \\
(5.2-65 .)\end{array}$ & $\begin{array}{c}18 . \\
(9.2-23 .)\end{array}$ \\
\hline $\begin{array}{l}\text { Carbono orgânico particulado } \\
\text { (COP, mg C/1) }\end{array}$ & $\begin{array}{c}2.6 \\
(1.3-5.6)\end{array}$ & $\begin{array}{c}1.4 \\
(0.99-1.9)\end{array}$ & $\begin{array}{c}3.9 \\
(2.4-5.6)\end{array}$ \\
\hline $\begin{array}{l}\text { Nitrogênio particulado } \\
(\mathrm{NP}, \mathrm{mg} \mathrm{N} / 1)\end{array}$ & $\begin{array}{c}0.16 \\
(0.094-0.27)\end{array}$ & $\begin{array}{c}0.17 \\
(0.036-0.33)\end{array}$ & $\begin{array}{c}0.49 \\
(0.32-0.66)\end{array}$ \\
\hline $\begin{array}{l}\text { Clorofila a } \\
(\mu \mathrm{g} / 1)\end{array}$ & $\begin{array}{c}4.3 \\
(0.1-9.4)\end{array}$ & $\begin{array}{c}7.7 \\
(2.0-21 .)\end{array}$ & $\begin{array}{c}52 . \\
(29 .-77 .)\end{array}$ \\
\hline $\begin{array}{l}\text { Profundidade de Secchi } \\
\text { (m) }\end{array}$ & $\begin{array}{c}0.22 \\
(0.15-0.25)\end{array}$ & $\begin{array}{c}0.95 \\
(0.90-1.1)\end{array}$ & $\begin{array}{c}0.90 \\
(0.60-1.1)\end{array}$ \\
\hline $\begin{array}{l}\text { Produtividade primária } \\
\left(\mathrm{g} \mathrm{C} / \mathrm{m}^{2} . \mathrm{d}\right)\end{array}$ & $\begin{array}{c}0.063 \\
(0.048-0.14)\end{array}$ & $\begin{array}{c}0.19 \\
(0.0600 .47)\end{array}$ & $\begin{array}{c}2.2 \\
(0.82-3.5)\end{array}$ \\
\hline
\end{tabular}

TABELA II. Composição taxonômica média do fitoplâneton do rio Negro e lago Janauacá. Cyanophyta $=$ al. gas cianofíceas. Chlorophyta $=$ algas verdes. Crytoph yta $=$ algas flageladas pequenas. Chrysophyta $=$ algas silicosas, inclusive diatomáceas.

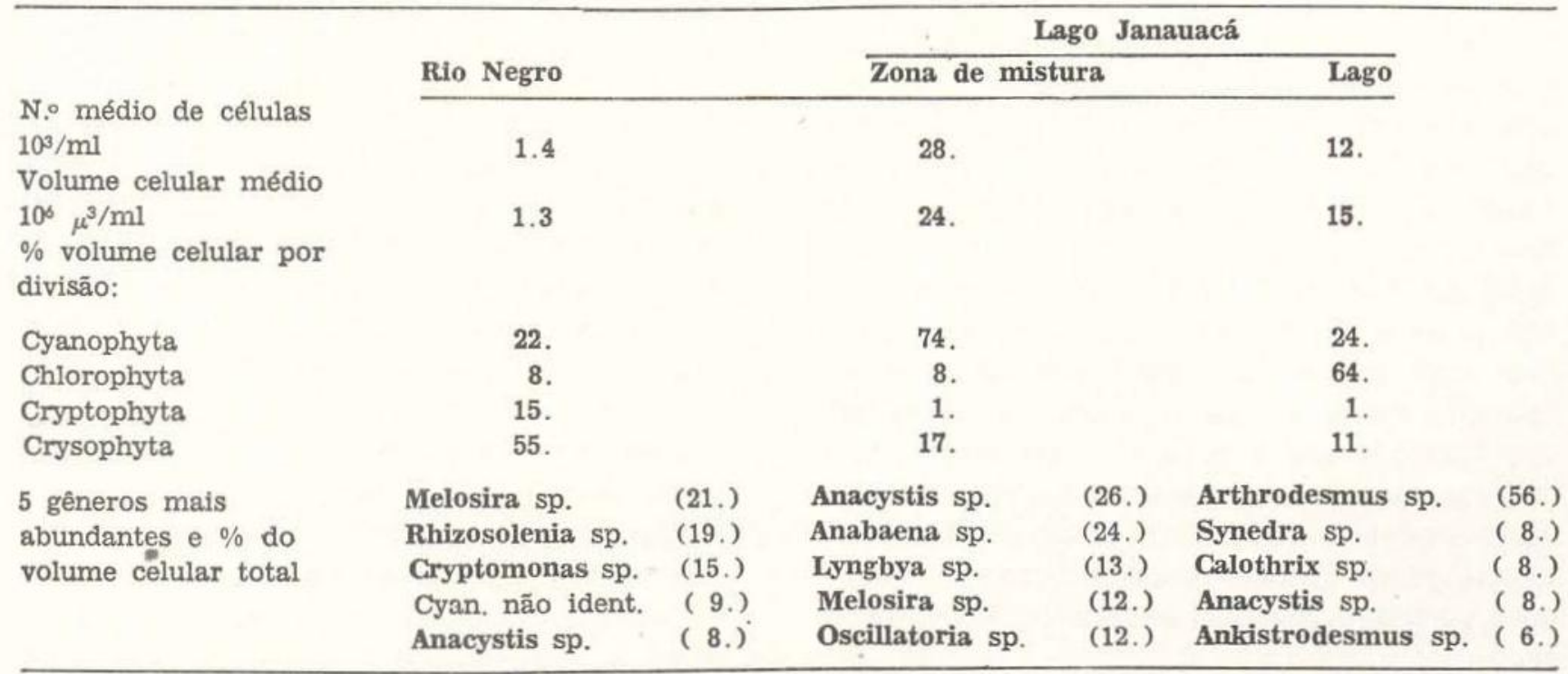


(Yentsch, 1975). A abundância de fitoplâcton, como indicada pela clorofila, foi a menor de todos os três ambientes, e a presença de micro-algas neste rio provavelmente resulta da entrada a partir de ambientes mais produtivos, tais como os lagos adjacentes (Schmidt, 1970). Tentativas de quantificar-se a comunidade de fitoplâncton no Solimões foram virtualmente impossíveis pela baixa quantidade de células e grande quantidade de outros materiais particulados.

No rio Negro, com sua água preta, os nutrientes minerais dissolvidos necessários para $\sigma$ crescimento do fitoplâncton eram muito menos abundantes do que no Solimões, particularmente $\Sigma \mathrm{CO}_{2}$. Entretanto, a razão atômica $\mathrm{C}: \mathrm{N}: \mathrm{P}$ de minerais inorgânicos no rio Negro sugere que o fosfato é o nutriente menos abundante dos três quando comparado com as necessidades do fitoplâncton baseado, em sua razão de composição C:N:P: de 100:16:1 (Redfield et al. 1963). Estes dados sugerem que o fosfato poderia ser limitante para o crescimento de algas no rio Negro. Entretanto, experiências de enriquecimento com fosfato não estimularam significativamente $(p>0,05)$ a absorção de ${ }^{14} \mathrm{C}$ relativamente aos controles não enriquecidos em medidas da produção primária. Tampouco a disponibilidade de dióxido de carbono influenciou significativamente ( $p>0,05)$ a taxa de fotossíntese no rio $\mathrm{Ne}$ gro, embora os dados na figura 2 mostrem um ciclo diária de $\mathrm{CO}_{2}$ total dissolvido nas águas superficiais movido pela absorção fotossintética e reabastecimento atmosférico (ou interno). Estes dados sugerem que, a despeito das baixas concentrações de fosfato e $\mathrm{CO}_{2}$, outros fatores ambientais controlam as taxas observadas de produção primária. A figura 1 sugere que a luz limita a fotossíntese nesta água altamente colorida, visto que a intensidade de luz reduzida durante tempestades de chuva diminuiu tanto a produção máxima observada na coluna d'água e, em menor grau, a produtividade total da coluna d'água (integrada ao longo da profundidade).

Sob condições de pouco vento, ocorreu uma estratificação da temperatura à profundidades de 0,5 a 1,0 m neste rio de baixa correnteza $(0,1-0,2 \mathrm{~m} / \mathrm{seg}$. $)$. Crescimento de fitoplâncton e exaustão do $\mathrm{CO}_{2}$ na camada su-

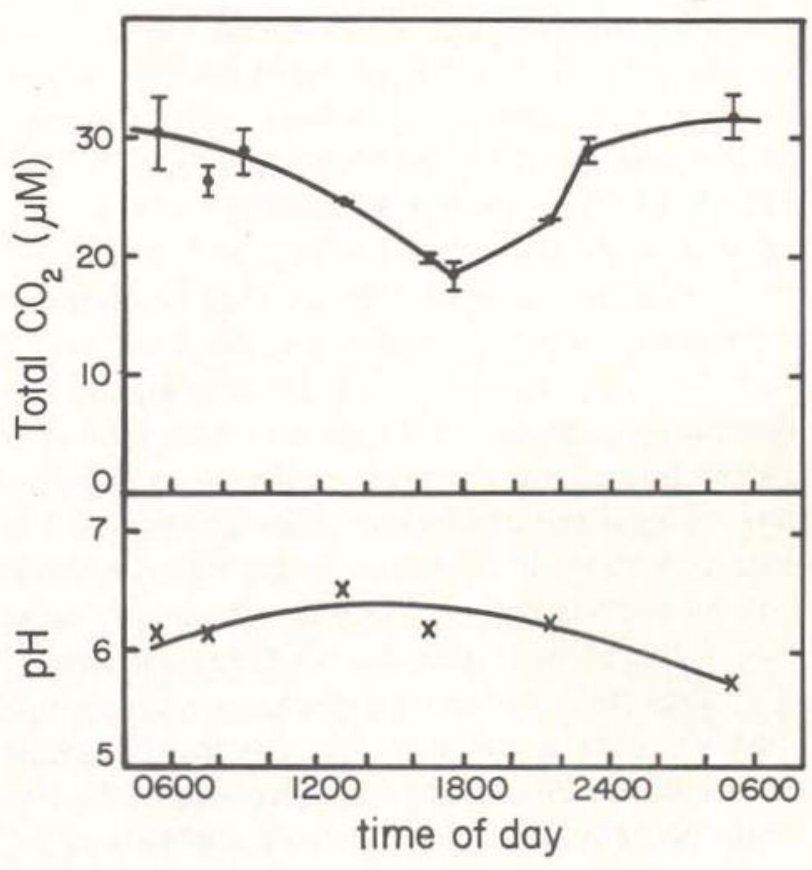

Fig. $2-\Sigma \mathrm{CO}_{2}$ e pH como uma função da hora do dia no baixo rio Negro, Brasil. As barras representam a amplitude de variação de duplicatas. A demanda fotossintética e o abastecimento atmosféri. co causa ciclos diários de $\Sigma \mathrm{CO}_{2}$.

perficial eram provavelmente favorecidos pela estratificação que, entretanto, poderia ser rapidamente destruída por ventos associados com tempestades de chuva, e usualmente desaparecia à noite.

Embora o baixo rio Negro seja de caráter mais lacustre do que o Solimões, o Negro, durante a área baixa, também parece ser um sistema limitado pela luz como o Solimões, face à profundidade (20-60 m), à estratificação efêmera, à pouca penetração da luz causada pela turbidez e cor (Tabela I), e ao efeito de níveis baixos de luz sob a fotossíntese (Fig. 1). Esta conclusão está em conflito com Schmidt (1976) que afirma que os nutrientes (não especificados) limitam a produção primária no rio $\mathrm{Ne}$ gro, embora nenhum dado seja apresentado. Entretanto, os níveis de produção primária medidos neste estudo comparam-se favoravelmente com aqueles relatados por Schmidt (1976) para a água baixa.

Água branca decantada foi amostrada no lago de Janauacá, um lago grande e raso, com 2-3 m de profundidade, conectando-se com o 
rio Solimões a área de $60 \mathrm{~km}$ a SW de Manaus. $O$ lago é muito produtivo, baixo em nutrientes minerais inorgânicos, e contém grandes concentrações de fitoplâncton, cơmo indicado pela clorofila e a contagem de células (Tabela II). Já que a produtividade primária é alta e os nutrientes inorgânicos são baixos, deve estar ocorrendo uma reciclagem intensiva de minerais no lago de Janauacá (mineralização de matéria orgânica e absorção dos minerais pelo fitoplâncton para formar nova matéria orgânica). Cálculos usando os dados da Tabela I e as proporções de composição atômica sugerem que os tempos de rotatividade (Turnover) para $\mathrm{N}$ e $\mathrm{P}$ inorgânicos são de 1-3 horas durante o dia. Este tipo de ecossistema de rápida reciclagem, com a maioria dos minerais ligados em forma de biomassa, é similar àquele da floresta na bacia amazônica (Stark, 1971a e b) .

No lago de Janauacá foram observadas densas populações de zooplâncton. Eram predominantemente copépodos e cladóceras, e estimou-se que estavam presentes numa densidade de 1-3 indivíduos por $\mathrm{ml}$, a partir do exame de amostras totais de água, e $13-15 \mathrm{~g}$ de peso fresco por $\mathrm{m}^{3}$, a partir de amostragens com rede. Ambas as estimativas da abundância do zooplâncton estão entre as maiores já relatadas em lagos (Hutchinson, 1967; Wetzel, 1975), não comparáveis às densidades mencionadas para o lago George, um lago raso e eutrófico na África (Ganf \& Blazka, 1974). Embora as velocidades de filtração possam variar em até duas ordens de grandeza, dependendo do tamanho do corpo e de variáveis ambientais como a temperatura, as velocidades são tipicamente em torno de $1 \mathrm{ml}$ por indivíduo por dia (Wetzel, 1975). Quando combinados com uma densidade estimada de 1-3 indivíduos por $\mathrm{ml}$, as estimativas da velocidade de filtração pelo zooplâncton predizem que a predação do fitoplâncton resulta numa renovação do mesmo $100-300 \%$ por dia. Esta estimativa da predação do fitoplâncton sugere que a densa população de zooplâncton é um dos principais mecanismos de regeneração de nutrientes para a produção primária no lago Janauacá, com sua intensa reciclagem. $O$ zooplânctơn também serve como üma fonte importante para a produção secundária de níveis tróficos superiores do lago, tais como os peixes.
Em fins de novembro, a estação chuvosa começa na bacia amazônica, e em dezembro o rio Amazonas estava subindo e inundando muitas áreas adjacentes, inclusive o lago de Janauacá. A medida que as águas turvas e ricas em nutrientes do rio penetravam no lago, uma floração de algas desenvolveu-se na zona de mistura das águas do lago e do rio. Uma remoção virtualmente completa de nitratos e fosfatos ocorreu na zona de mistura à medida que as algas cianofíceas experimentavam um aumento de cinco vezes no volume de células e as diatomáceas dobraram (veja Tabela II). As conseqüências da invasăo pelo río foram tratadas em outro lugar (Fisher \& Parsley, 1978), e as conseqüências biológicas para o plấncton do lago de Janauacá estão representadas na Fig. 3. O volume de zooplânctơn mostra essencialmente um comportamento de di-

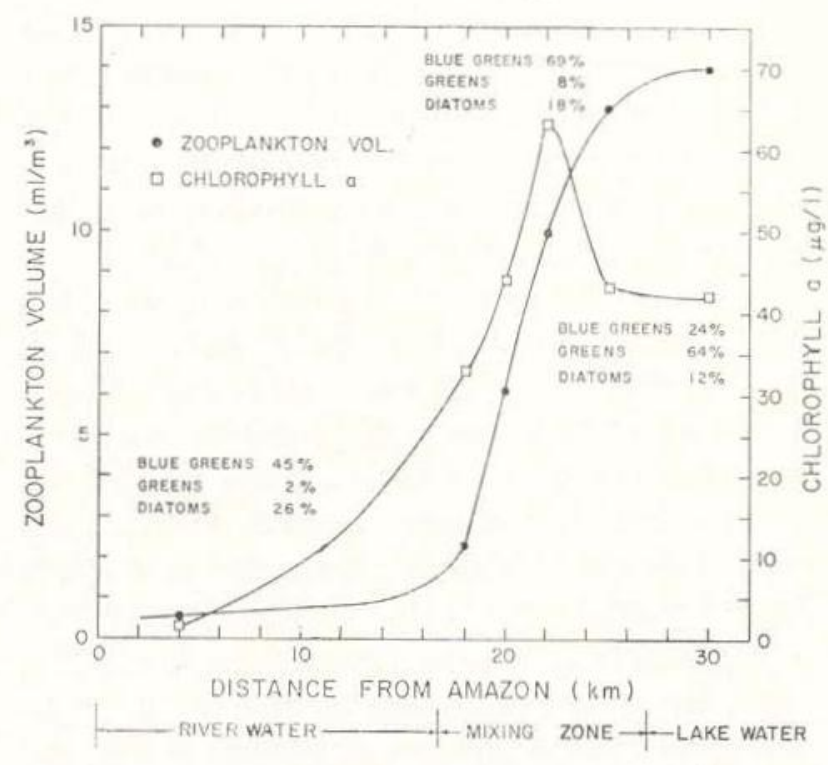

Fig. 3 - Invasāo do lago Janauacá pela água do rio Amazonas e as consequiências biológicas sobre o plâncton. Estes dados foram obtidos sobre um transecto do lago em 9 de dezembro de 1976. O Amazonas havia subido cerca de $1,5 \mathrm{~m}$ em três semanas e havia penetrado $20 \mathrm{~km}$ dentro do lago Janauacá. A composição taxonômica do fitoplâncton é indicada para a água do lago, zona de mistura e água do rio. Os números referem-se à porcentagem do volume celular total de cada um dos grupos principais. As cianofíceas sofreram um aumento de cinco vezes no volume celular, e as diatomáceas ultrapassaram o dobro da quantidade inicial na zo. na de mistura enriquecida de nutrientes, dos dois tipos d’água. 
luição conservativa provavelmente como um resultado da rapidez da mistura em relação às taxas de crescimento e mortalidade do zooplâncton. Em contraste, o fitoplâncton (clorofila a) mostra uma resposta não-conservativa (i.e., crescımento) ao nitrato e fosfato contribuído pela água do rio. É interessante notar que tanto as diatomáceas quanto as cianofíceas aumentaram em abundância na zona de mistura apesar da reduzida produtividade primária global dada a turbidez da água advectada do rio. Alívio da predação pelo zooplânctơn na zona de mistura pode ter sido parcialmente responsável.

Os dados agrupados de todos os três ambientes são mostrados nas Fig. 4-7. Apesar das condições físicas e químicas díspares (Tabela I e texto), processos biológicos similares puderam ser identificados em cada área. Por exemplo, os dados na Fig. 4 sugerem uma relação constante entre clorofila a e fixação fo. tossintética de carbono sob saturação de luz

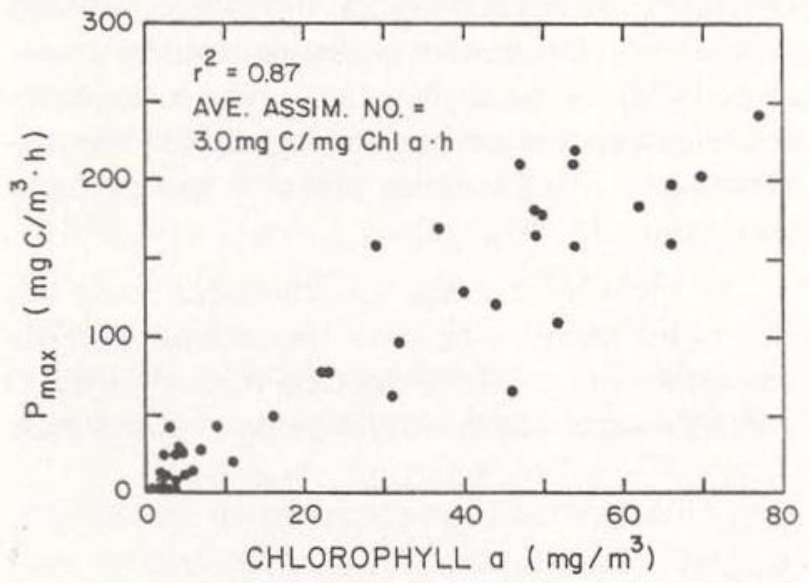

Fig. 4 - Fixação fotossintética de carbono sob saturação de luz (P $\max$ ) e clorofila a. A correlação é altamente significativa $(P<0,01)$ e sugere um número de assimilação relativamente constante (P max/Clorof, a).

$\left(P_{\max }\right)$. Esta relação indica um número de assimilação média ( $P_{\max } /$ clor a) de $3,0 \mathrm{mgC} / \mathrm{mg}$ clor ah para todas as incubações de produtividade onde um valor de saturação de luz pode ser distinguido claramente (maior que $90 \%$ de todas as incubações).

A Fig. 5 ilustra a relação entre a produtividade primária (produção integrada pela profundidade, $\mathrm{mgC} / \mathrm{m}^{2} . \mathrm{h}$ ) e a produção em satu- ração de luz $\left(\mathrm{P}_{\max }, \mathrm{mgC} / \mathrm{m}^{3} . \mathrm{h}\right)$, a última obtida usualmente dentro dos primeiro $0,5 \mathrm{~m}$ superficies da coluna d'água. A produção primária no lago Janauacá é intensiva no volume, o que é típico para corpos d'água rasos (Hutchinson, 1967). A razão média entre a produção primária integrada pela profundidade (produtividade) e a produção primária máxima (a inclinação da Fig. 5) é 0,97 .

Os dados na Fig. 5 foram submetidos à análise de variância usando o Sistema de Análise Estatística (SAS). O seguinte modelo, incluindo as profundidades de Secchi, foi produzido :

(Produtividade Primária, $\mathrm{mgC} / \mathrm{m}^{2}$. d) $=$ - 35,7 + 8,899 $\left(P_{\max }, \mathrm{mgC} / \mathrm{m}^{3} \cdot \mathrm{d}\right)+57,4$ (profundidade de Secchi) .

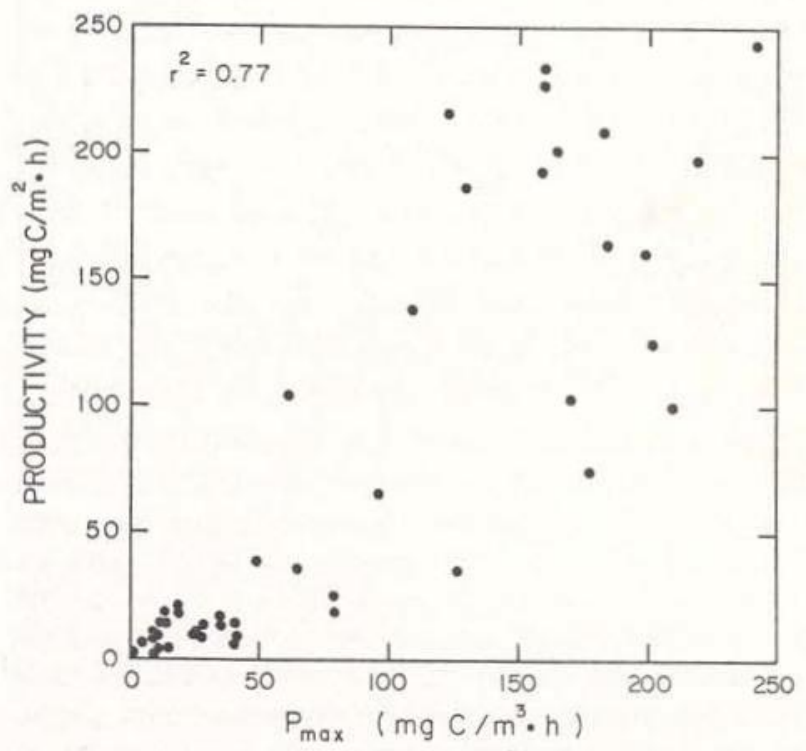

Fig. 5- Produtividade primária (produção integrada em toda a profundidade) e produção sob saturação lumincsa $(\mathrm{P} \max )$. A correlação é significante $(P<0,05)$.

Este modelo tem um coeficiente de determinação $\left(r^{2}\right)$ de 0,87 , indicando que $87 \%$ da variação na produtividade primária (integrada pela profundidade) pode ser explicada por sua relação com $P_{\max } \mathrm{e}$ com a profundidade de Secchi. Este modelo pole ser usado para prever a produtividade a partir de leituras de profundidade de Secchi e uma incubação na superfície $(>0,5 \mathrm{~m})$, onde $P_{\max }$ ocorreu invariavelmente. 
A relação entre produção primária particulada e produção primária dissolvida ("excretata") é mostrada na Fig. 6. A produção dissolvida foi uma fração pequena da produção particulada, variando entre $1,7-11 \%$, sendo em média $2,8 \%$.

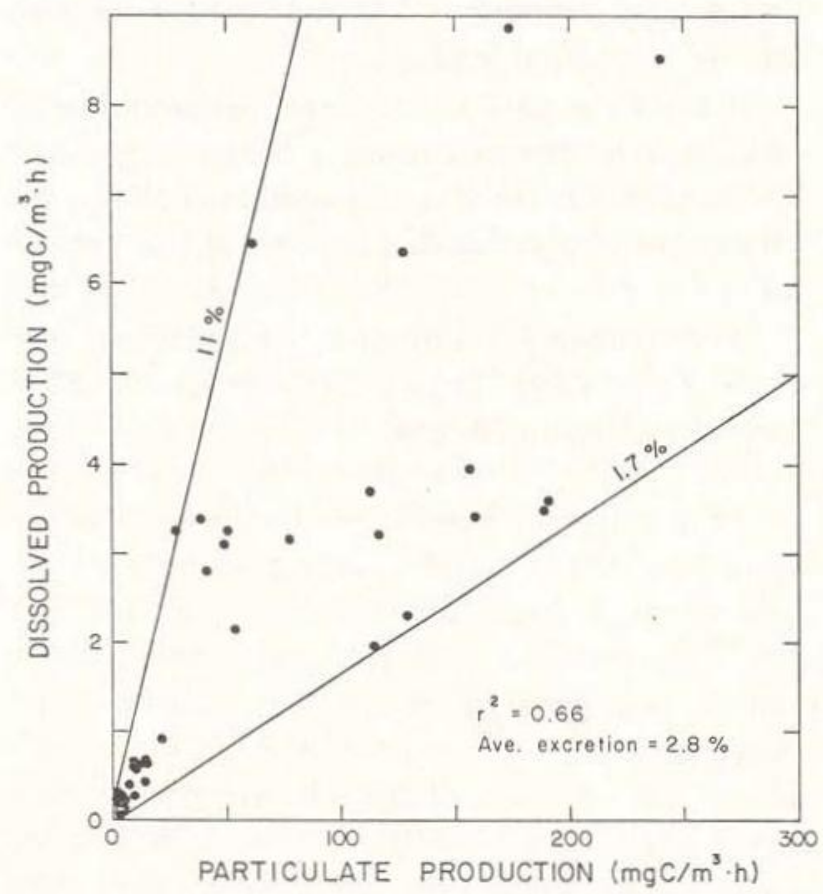

Fig. 6-Produção primária dissolvida e particulada. Produção dissolvida (também conhecida como "excreção" (Sharp, 1977) resulta da perda pelas células do fitoplâncton de moléculas orgânicas de baixo peso molecular produzidas fotossinteticamente durante a incubação (e portanto marcadas com ${ }^{14} \mathrm{C}$ ). A produção dissolvida representou uma pequena fração da produção particulada em todas as incubações.

A Fig. 7 também é uma composição dos dados de todos os três ambientes. Estes dados são essencialmente de situaçōes de equilíbrio dinâmico aproximado que tendiam a favorecer ou (1) o desenvolvimento de uma vigorosa comunidade planctônlca e utilização de nitrato (um ambiente lacustrino), ou (2) a supressão da absorção biológica e a persistência de elevadas concentrações de nitrato (condições fluviais). A foz lacustre de baixa correnteža (Sioli, 1964) do rio Negro com suas concentrações intermediárias de nitrato (Tabela I) tende a cair no meio do gráfico (1-6 uM
$\mathrm{NO}_{3}$ ), indicando um caráter biológico parcialmente expresso. Vários grupos de dados foram excluídos da Fig. 7 que resultou de mistura da água de lagos apresentando altos teores de clorofila com águas de rios apresentanto altos teores de nitrato. Estes dados eram caracterizados por alta turbidez e altas concentrações de feopigmentos (compostos da clorofila a degradada), indicando uma população de fitoplâncton senescente e condições de em não equilíbrio dinâmico.

\section{DIscussão}

Dados foram apresentados (Tabela I e texto) que ilustram o caráter físico e químico altamente divergente de três ambientes aquáticos na bacia da Amazônia Central e as diferenças ambientais foram refletidas nos processos biológicos associados com a produção primária (Fig. 4-7). Embora Sioli (1964 e 1975) tenha enfatizado a importância das diferenças químicas entre os tipos de água, durante o limitado período de tempo do presente estudo (nov.dez., 1976) as condições físicas de turbulência e luz pareceram ser mais importantes em determinar a habilidade do plâncton em explorar seu ambiente (Fig. 7).

A invasão do lago de Janauacá pelo rio Solimões representa uma importante entrada advectiva de nitrato e fosfato para o lago. O nível da água flutua de 2-3 $\mathrm{m}$ de profundidade

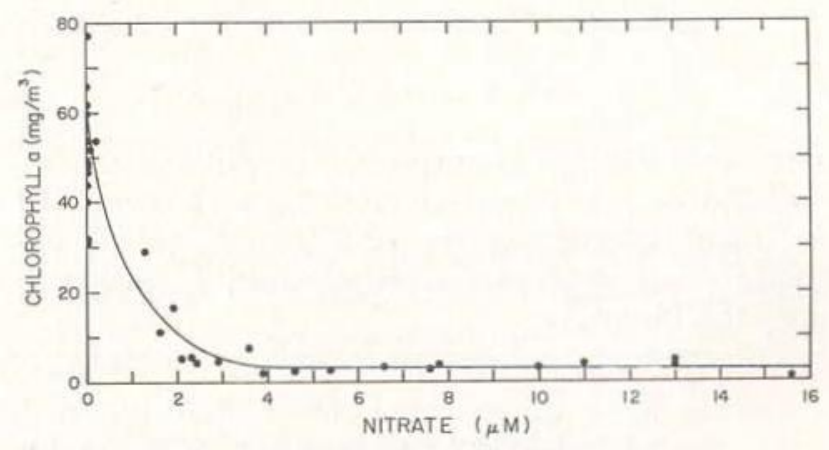

Fig. 7 - Clorofila a e concentração de nitrato em três ambientes. As estaçōes do lago agrupam-se na extremidade esquerda, o rio Solimōes tem mais do que $6 \mu \mathrm{m}$ de nitrato e o rio Negro é intermediário. Este gráfico ilustra a dominância relativa de processos físicos e biológicos nos três ambientes, condiçōes mediadas biologicamente para a esquerda, e condições mediadas fisicamente para a direita. 
durante as águas baixas até 10-12 m durante as águas altas, impulsionado primariamente pelas mudanças de nível d'água no rio Solimões. Se a entrada das bacias hidrográficas locais é pequena em comparação com a entrada do rio, então o lago é enchido e drenado (lavado) cada ano em aproximadamente $80 \%$ pelo rio vizinho. Embora o impacto imediato da invasão do rio fosse uma diminuição na produtividade primária aos níveis de luz reduzidos na água turva, uma vigorosa comunidade planctônica desenvolvera-se no lago subseqüentemente à invasão do ano anterior (dezembro a junho), presumivelmente pela sedimentação das partículas sob as condições menos turbulentas do lago. A entrada anual de nutrientes, acoplada com os rápidos ciclos minerais nas temperaturas elevadas $\left(\sim 30^{\circ} \mathrm{C}\right)$ parece manter a alta fertilidade da água do lago.

Padrões similares de ciclos de nutrientes minerais têm sido encontrados em outros sistemas aquáticos. Lagos em ferradura isolados do baixo Mississipi têm uma dinâmica de nutrientes e plâncton similar às do lago de Janauacá, como um resultado da inundação pelo rio (L.H. Kaufman, com. pess.). Um desenvolvimento intenso do plâncton segue a introdução de água nova do Mississipi após o restabelecimento da isolação; entretanto, estes lagos são lavados rapidamente (1-3 dias) porque eles são abertos em ambas as pontas para o rio. Durante os elevados fluxos fluviais da primavera, os estuários também recebem grandes entradas de nutrientes que são posteriormente exauridas e recicladas, na maior parte via sedimentos (Williams, 1972; Hargrave, 1973). Águas superficiais dos oceanos e lagos são enriquecidas durante o inverno pela destruição do termoclino e mistura vertical com a água do fundo rica em nutrientes. Florações de plâncton então seguem o restabelecimento de um termoclino e esgotam os minerais inorgânicos dissolvidos nas camadas superiores iluminadas (Hutchinson, 1967; Sverdrup, Johnson \& Flrming, 1942). Embora certas características são únicas de cada ambiente, os ciclos de nutrientes observados no lago Janauacá são semelhante aos de outros sistemas aquáticos, que podem ser caracterizados por um enriquecimento sazonal, seguido pelo esgotamento e reciclagem, particularmente sob condições de baixos fluxos (lavagem) e baixas turbulência e turbidez (mais elevados níveis de luz).

Se os altos níveis de produção primária pelo fitoplâncton que ocorrem no lago de Janauacá são representativos, os lagos que marginam o rio Amazonas podem ser uma das maiores fontes de material orgânico para suportar níveis tróficos mais altos nas áreas de água branca. Outras fontes primárias de compostos de carbono reduzido são a liteira terrestre (Fittkau, 1964) e as gramíneas emergentes dos lagos e rios de água branca ("Capins flutuantes" Junk, 1970). Estas últimas não são encontradas em águas pretas, e sua ausência, juntamente com a produtividade primária mais baixa, pode ser parcialmente responsável pela relativa pobreza biológica das regiões de água preta da região (Janzen, 1974). Marlier (1967) estimou que a produtividade primária dos capins flutuantes é aproximadamente $12 \mathrm{~g} \mathrm{C} / \mathrm{m}^{2} . \mathrm{d}$ durante os seis meses da época de crescimento destas plantas vasculares. Além disso, a produção total integrada pela área parece exceder à do fitoplâncton, uma situação similar à dos pântanos salgados nos estuários do leste dos EE.UU. (Williams, 1972). Entretanto, as plantas vasculares, ao contrário do fitoplâncton, não são diretamente consumidas e contribuem para a estrutura trófica via canal detrítico-heterotrófico. Dada a respiração adicional estas condições reduzem a eficiência do fluxo de carbono para os níveis tróficos superiores e diminuem a importância aparente da produtividade primária dos capins flutuantes para a economia total do lago. Os tempos de renovação do carbono para o fitoplânctơn e capins flutuantes apoiam esta opinião. Usando os dados de produtividade e carbono orgânico particulado (COP) na Tabela I, o tempo de renovação do COP no lago de Janauacá (presumivelmente derivado em sua maior parte do fitoplâncton) é 1,4 a 14 dias. Cálculos comparáveis para os capins flutuantes usando os dados de Junk (1970) e Marlier (1967), dão como resultado 23 a 160 dias, concluindo-se que o carbono representa $45 \%$ do peso seco das plantas. Embora seu papel como um habitat 
protetor seja claro depois das observações de Junk (1973), o papel trófico dos capins flutuantes na bacia Amazônica é menos bem definido.

É claro, a partir da presente pesquisa, que a produção do fitoplâncton em lagos semelhantes ao de Janauacá é suficiente para prover base trófica para uma atividade pesqueira viável, e a estrutura trófica detrífica gerada pelos capins flutuantes deve aumentar a produção de algas. Entretanto, a importância relativa destas duas fontes de matéria orgânica é desconhecida. As áreas de água branca da Amazônia são bem conhecidas pela abundância e diversidade de seus peixes, embora a estrutura trófica que suporta este recurso pesqueiro relativamente inexplorado seja pobremente conhecida. Tanto o Peru como o Brasil estão a procura de esquemas de aquacultura para a bacia amazônica, e lagos como o de Janauacá são muito promissores para um tal desenvolvi. mento.

\section{AGRADECIMENTOS}

Agradeço aos Drs. Austen Riggs, Joseph Bonaventura e John D. Costlow por terem tornado possível minha participação na expedição Amazon IV "Alpha Helix". Agradeço também a Ton Forhan, gerente do programa, o capitão e a tripulação do "Alpha Helix", o governo brasileiro pela permissão de operar o navio em águas amazônicas, e especialmente a Patty Parsley, por ter feito as contagens de fitoplâncton. Respeitando um acordo com o governo brasileiro, uma versão em português deste artigo aparecerá na Acta Amazonica. Esta pesquisa recebeu o apoio das bolsas de estudo PCM 75-06451 e OCE 76-82084 da Nacional Science Foundation, a última durante a preparação do manuscrito e análise das amostras remetidas aos EE. UU.

\section{SUMMARY}

Three aquatic environments of the Central Amazon Basin were sampled during the low water phase: Rio Solimões (Amazon), rio Negro, and lago Janauaca. In the nutrient-rich rio Solimões, primary productivity averaged $0.063 \mathrm{gC} / \mathrm{m}^{2}$. d, but net growth of phytoplankton is impossible because of the depth, poor light penetration, and current-driven turhulence. In the chemically-poor Rio Negro, a daily cycle of $\mathrm{CO}_{2}$ was caused by photosynthetic demand in surface waters, and primary productivity averaged $0.19 \mathrm{gC} / \mathrm{m}^{2}$. d. In Lago Janauaca, a lake bordering the Solimões, nutrients were low in concentration and intensively recycled; large phytoplankton populations produced up to 3.5 $\mathrm{gC} / \mathrm{m}^{2} \cdot \mathrm{d}$ (average $=2.2$ ). The ten meter annual change in water level of the Amazon river provides and drains most of the water in lakes along the river. During storage of river water in the lakes the particulates settle and the dissolved inorganic nutrients are converted to organic forms by intense phytoplankton growth. These lakes may be a major source of organic matter for the river ecosystem.

\section{BIBLIOGRAFIA}

Davis, L.C.

1964 - The Amazon's rate of flow. Nat. Hist., 73(6) : 15-19.

Fisher, T.R. \& PARSLEy, P.A.

1977 - Amazon lakes: water storage and mineral stripping. (No prelo)

FITTKAU, E.J.

1964 - Remarks on limnology of central-Amazon rain-forest streams. Verh. Internat. Verein. Limnol., 15 : 1092-1096.

FORSTER, $\mathbf{K}$.

1969 - Amazonische desmidieen. I. Areal Santarem. Amazoniana, $2:$ 5-232.

GANF, G.G. \& BLAZKA, P.

1974 - Oxygen uptake, ammonia and phosphate excretion by zooplankton of a shallow equatorial lake (Lake George, Uganda) Limnol. Oceanogr., 19 : 313-325.

GIBBS, R.J.

1967 - The geochemistry of the Amazon River system: Part I: The factore that control the salinity and the composition and concentration of the suspended solids. Bull. Geol. Soc. America, 78 : 1203-1232.

Gresswell, R.K. \& Huxley, A. ed.

1964 - Standard encyclopedia of the world's rivers and lakes. London, Weidenfeld \& Nicolson Ltd.

HARgRave, B.T.

1973 - Coupling carbon flow through some pelagic and benthic communities. J. Fish. Res. Board Can., $30: 1317-1326$.

HunTSMan, S.A.

1974 - An evaluation of optimal conditions for determination of primary production. CUEA Newsletter, $3: 8-13$. 
Hutchinson, G.E.

1967 - A Treatise on Limnology; introduction to lake biology and the limnoplankton. New York, John Wiley \& Sons: v. 2. $660 \mathrm{p}$.

JANZEN, D.

1974 - Tropical blackwater rivers, animals, and most fruiting by the Dipterocarpaceae. Biotropica, $6: 69-103$.

JUNK, W.J.

1970 - Investigations on the ecology and production-biology of the "floating meadows" (Paspalo-Echinochloetum) on the Middle Amazon. Amazoniana, 2(4): 449-495.

1973 - Investigations on the ecology and production-biology of the "floating meadows" (Paspalo-Echinochloetum) of the midle Amazon. Part. II. The aquatic fauna in the root zone of floating vegetation. Amazoniana, 4:9-102.

KIEFER, D. \& STRICKLAND, J.D.H.

1970 - A comparative study of photosynthesis in seawater samples incubated under two types of light attenuator. Limnol. Oceanogr., $15: 408-412$.

KLINGE, $\mathrm{H}$.

1967 - Podzol soils: a source of blackwater rivers in Amazonia. Limnolog., 3:117-125.

KOROLEFF, F

1969 - Direct determination of ammonia in natural waters as indophenol blue. Int. Con. Explor. Sea. C.M., 1969/C:9.

LORENZEN, C.J.

1969 - Determination of chlorophyll and pheopigments: spectrophotometric equations. Limnol. Oceanogr., $12: 343$.

MARLIER, G.

1967 - Ecological studies of some lakes of the Amazon Valley. Amazoniana, 1(2):91-115.

Menzel, D.W. \& Vaccaro, R.F.

1964 - The measurement of dissolved organic and particulate carbon in sea water. Limnol, Oceanogr., 9 : 138-142.

Oltman, R.E.; Sternberg, H.O.R.; Ames, F.C. \& Davis, L.C.

1964 - Amazon River investigations. Reconnaissance measurements of july, 1963. U.S. Geol. Surv. Circ., 486:15.

Prescott, G.W.

1962 - Algae of the Western Great Lakes area. 2nd edition. Iowa, Dubuque.

Redfield, A.C.; KetchUM, B.H. \& Richards, F.A.

1963 - The influence of organisms on the composition of sea-water. In: The Sea (N.N. Hill, ed.) New York, Intercience, vol. 2 : 67-77.
SCHMIDT, G.W

1970 - Numbers of bacteria and algal and their interlations in some Amazonian waters. Amazoniana, 2(4) : 393-400.

1973a - Primary production of phytoplankton in the three types of Amazonian waters. II. The limnology of a tropical flood plain lake in Central Amazonia (Lago do Castanhó) Amazoniana, $4: 138-203$.

$1973 \mathrm{~b}$ - Primary production in the three types of Amazonian waters. III. Primary productivity of phytoplankton in a tropical flood plain lake of central Amazonia, Lago do Castanho, Amazonas, Brazil. Amazonia, $4: 379-404$.

1976 - Primary production of phytoplankton in the three types of Amazonian waters. IV. On the primary productivity of phytoplankton in a bay of the lower Rio Negro (Amazonas, Brazil) Amazoniana, $5: 517-528$.

Scott, A.M.; Gronblad, R.; Croasdale, H. \& Sioli, H. 1965 - DESMIDS from the Amazon Basin, Brazil. Acta Botanica Fenica, 69: 1-94.

SHARP, J.H.

1977 - Excretion of organic matter by marine phytoplankton: do healthy cells do it? Limnolog. Oceanogr., $22: 381-399$.

SroLI, H

1964 - General features of the limnology of Amazonia. Verh. Internat. Verein. Limnol., 15 : 1053-1058.

1975 - Tropical river: the Amazon. In: River Ecology (B.A. Whitton) Los Angeles, Univ. of Cal. Press. pp. 461-488.

Stark, N.M.

1971a - Nutrient cycling I. Nutrient distribution in some Amazonian soils. Trop. Ecol.. $12: 24-50$

$1971 b$ - Nutrient cycling II. Nutrient distribution in some Amazonian vegetation. Trop. Ecol., $12:$ 177-201.

Strickland, J.D.H. \& Parsons, T.R

1972 - A practical handbook of seawater analysis. Fish. Res, Bd. Can. Bull., 167:1-130. (2nd edition)

SVERdRUP, H.U.; JoHNSON, M.W. \& Fleming, R.H.

1942 - The Oceans, their Physics, chemistry and general biology. Englewood Cliffs, New Jersey, Prentice-Hall.

Thomasson, K.

1971 - Amazonian algae. Inst. Roy. Soc. Nat. Belg. Memoires, 2(86) : 1-57.

VOLLENWEIDER, R.A. ed.

1974 - A manual on methods for measuring primary production in aquatic environments. IBP Handbook, n. 12. 2nd ed. London, Blackwell Scientific Pub. 
WETZEL, R.G.

1975 - Limnology. Philadelphia, W.B. Saunders. $743 \mathrm{p}$.

WHITFORD, L.A. \& SCHUMACHER, G.J.

1973 - A manual of freshwater algae. Raleigh, Sparks.

WILLIAMS, R.B.

1972 - Nutrient levels and phytoplankton productivity in the estuary. In: Proceedings of the Coastral Marsh and
Estuary Management Symposium, L.S.U. (R.H. Chabreck) Baton Rouge, Div. Continuing Education.

YeNTSCH, C.S.

1975 - Critical mixing depth: a problem in the measurement of respiration. In: Respiration of Marine Organisms TRIGOM, (CECH, J.J.; BRIDGES, D.W. \& HORTON, D.B. ed.) South Portland, Maine. p. 1-10. 